\title{
COMPARISON OF INTRAVENOUS KETAMINE, CLONIDINE OR DEXMEDETOMIDINE PRIOR TO SUBARACHNOID BLOCKADE FOR CONTROL OF SHIVERING
}

\author{
Shreyavathi R ${ }^{1}$, A. K. Kavitha², Raghavendra Rao R. S³, Bhaskara B ${ }^{4}$
}

\section{HOW TO CITE THIS ARTICLE:}

Shreyavathi R, A. K. Kavitha, Raghavendra Rao R. S, Bhaskara B. "Comparison of Intravenous Ketamine, Clonidine or Dexmedetomidine Prior to Subarachnoid Blockade for Control of Shivering". Journal of Evolution of Medical and Dental Sciences 2014; Vol. 3, Issue 45, September 18; Page: 11021-11027,

DOI: $10.14260 /$ jemds/2014/3438

ABSTRACT: AIMS AND OBJECTIVES: This prospective randomized, comparative, placebo controlled study was designed to evaluate the efficacy of intravenous Ketamine, Clonidine, and Dexmedetomidine prior to subarachnoid block in control of shivering. METHODS: This study was conducted in 100 ASA grade I and II patients. They were allocated into four groups of 25 each and were given saline in control (Group S), Ketamine $0.5 \mathrm{mg} / \mathrm{kg}$ (group K), Clonidine $75 \mu \mathrm{g}$ (group C) and Dexmedetomidine $1 \mu \mathrm{g} / \mathrm{kg}$ (group D) intravenously prior to subarachnoid block. Conventional subarachnoid block was performed with $3 \mathrm{ml}(15 \mathrm{mg})$ of $0.5 \%$ Bupivacaine heavy in all patients under aseptic precaution. Hemodynamic parameters, temperature, onset of action, duration of sensory block and sedation score were recorded. RESULTS: There was no incidence of statistically significant shivering in Group K, C, D. The sedation score was Grade 3 in 21 patients in group D $(\mathrm{P}<0.001)$ as compared with the other groups. CONCLUSION: Intravenous Dexmedetomidine, Ketamine or Clonidine was effective in controlling shivering without any major hemodynamic changes. Dexmedetomidine group had an added advantage of higher sedation score.

KEYWORDS: Ketamine, clonidine, dexmedetomidine, shivering.

INTRODUCTION: The normal human core temperature ranges from $36.5^{\circ} \mathrm{C}$ to $37.5^{\circ} \mathrm{C} .1^{\text {Thermal }}$ inputs are integrated at the level of the anterior hypothalamus, which compares peripheral information with a threshold value, or the set-point. Temperatures higher than this set point will trigger responses to cool the body, while temperatures lower than this set point will activate reflexes to warm the body. ${ }^{2}$ Both general and regional anaesthesia is known to affect the efficiency of this homeostatic system and may result in different degrees of perioperative hypothermia. Regional anaesthesia also decreases this threshold by $0.5^{\circ} \mathrm{C}$, triggering vasoconstriction and shivering above level of block. ${ }^{3}$

This reduction in threshold is proportional to the number of spinal segments blocked, advanced age and high-level spinal blockade. ${ }^{4}$ Shivering is defined as an involuntary, repetitive activity of skeletal muscles. Spinal anesthesia significantly impairs the thermoregulation system by inhibiting tonic vasoconstriction, which plays a significant role in temperature regulation. ${ }^{5}$ Spinal anesthesia also causes redistribution of core heat from the trunk (below the block level) to the peripheral tissues. These two effects predispose patients to hypothermia and shivering. ${ }^{6}$

Perioperative hypothermia and shivering is one of the frequent, undesirable and unpleasant complications of both general and regional anaesthesia. The incidence of shivering is up to $40-60 \%$ even in regional anaesthesia. ${ }^{7}$ Shivering increases oxygen consumption, lactic acidosis, carbon dioxide production, and metabolic rate by up to $400 \% .^{8-9}$ 
Perioperative hypothermia and shivering is usually prevented by physical methods like surface warming and pharmacologically by drugs like pethidine, tramadol, and clonidine etc.

Various opioid and non-opioid agents were used to prevent and treat shivering, but they are not without side effects like hemodynamic instability, respiratory depression, nausea and vomiting.

This prospective randomized, comparative, placebo controlled study was designed to evaluate the efficacy of intravenous Ketamine, Clonidine, and Dexmedetomidine prior to subarachnoid block in control of shivering

METHODS: After obtaining institutional approval and written consent from all patients, this prospective, randomized, comparative and placebo controlled study was carried out in Bangalore Medical College and Research Institute from September 2013 to November 2013, one hundred ASA status I and II, patients between the ages of 18-60 years who were undergoing elective infra umbilical surgery under spinal anesthesia.

Patients with thyroid diseases, cardiopulmonary diseases, neuromuscular diseases, psychological disorders or having contraindications to spinal anaesthesia were excluded from the study. Also, patients on narcotics, sedatives or any medication likely to alter thermoregulation, patients with recent history of febrile illness and those with history of malignant hyperthermia were excluded.

The temperature of the operating room was maintained at $22 \pm 2^{\circ} \mathrm{C}$. All the patients were in fasting state for 6-8hrs before anaesthesia, and were pre-loaded with Ringer lactate $10 \mathrm{~mL} / \mathrm{kg}$ before conducting neuraxial blockade. Pre-warmed intravenous fluids to $37^{\circ} \mathrm{C}$ using a blood warmer unit were used intra operatively. Following the guidelines for asepsis conventional subarachnoid blockade was performed at either the L3-4 or L4-5 interspaces using a 25 gauge Quincke's spinal needle.

\section{Patients were randomised into four groups of 25 each, Namely:}

- Group C: Clonidine -Patients received clonidine $75 \mu \mathrm{g}$ i.v. diluted to $10 \mathrm{~mL}$ in saline

- Group K: Ketamine -Patients received ketamine $0.5 \mathrm{mg} / \mathrm{kg}$ i.v. diluted to $10 \mathrm{~mL}$ in saline

- Group D: Dexmedetomidine- Patients received Dexmedetomidine $1 \mu \mathrm{g} / \mathrm{kg}$ i.v. diluted to $10 \mathrm{~mL}$ in saline

- Group S: Control-Patients received $10 \mathrm{~mL}$ normal saline just before the subarachnoid blockade.

The following data were recorded: demographic data, onset of sensory blockade, highest level of sensory blockade, quality of motor blockade according to the Bromage scale, hemodynamic parameters, temperature, shivering and sedation.

Shivering was graded on a scale similar to that validated by Tsai and $\mathrm{Chu}^{8}: 0=$ no shivering, 1 = piloerection or peripheral vasoconstriction but no visible shivering, 2 = muscular activity in only one muscle group, $3=$ muscular activity in more than one muscle group but not generalized and 4 = shivering involving the whole body. If shivering occured, it was graded and recorded.

If the grade was 3 or 4 after 15 min from the administration of the tested prophylactic drug, it was considered severe shivering and rescue treatment in the form of Inj.Tramadol $25 \mathrm{mg}$ was given intravenously. 


\section{Sedation was graded using Ramsay sedation scale:}

1. Patient is anxious and agitated or restless, or both.

2. Patient is cooperative, oriented and tranquil.

3. Patient responds to commands only.

4. Patient exhibits brisk response to light glabellar tap or loud auditory stimulus.

5. Patient exhibits a sluggish response to light glabellar tap or loud auditory stimulus.

6. Patient exhibits no response.

Parameters were recorded at second minute after subarachnoid block and there after every five minutes till 60 minutes and once in ten minutes then onwards till 90 minutes.Any other side effects was recorded and properly treated e.g. bradycardia, hypotension, nausea, vomiting and hallucination.

Statistical Analysis: Student's t-test was used to analyze of demographic data and other continuous variables. Mood's test for medians, the $\chi 2$ test and Fisher's exact test were used when appropriate. $\mathrm{P}$ $<0.05$ was taken to be significant

RESULTS: The patient characteristics in the two groups were comparable with regard to age, sex, weight and height.

\begin{tabular}{|l|c|c|c|c|}
\hline & Group C & Group D & Group K & Group S \\
\hline Age (years) & $45.7 \pm 11.3$ & $33.86 \pm 10.8$ & $31.23 \pm 10.1$ & $44.5 \pm 11.08$ \\
\hline Sex M/F & $21 / 4$ & $18 / 7$ & $17 / 8$ & $14 / 11$ \\
\hline Weight $(\mathrm{kg})$ & $61.24 \pm 5.93$ & $63.34 \pm 7.17$ & $62.44 \pm 4.48$ & $61.84 \pm 10.20$ \\
\hline Height $(\mathrm{cm})$ & $160.36 \pm 3.60$ & $161.16 \pm 3.87$ & $162.12 \pm 3.28$ & $160.68 \pm 3.94$ \\
\hline \multicolumn{5}{|c}{ Table 1 } \\
\hline
\end{tabular}

On comparison of Hemodynamic parameters there were no significant changes among the four groups. [Figures 1-2]

There was no significant fall in Saturation in any patients belonging to any groups.

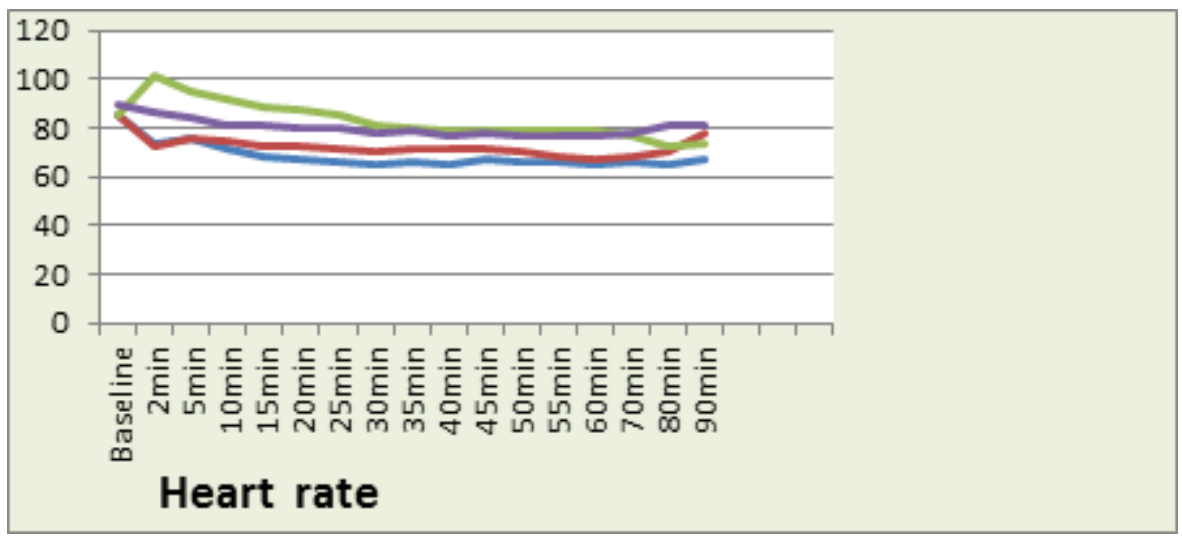

Figure 1: Trends in Heart rate 


\section{ORIGINAL ARTICLE}

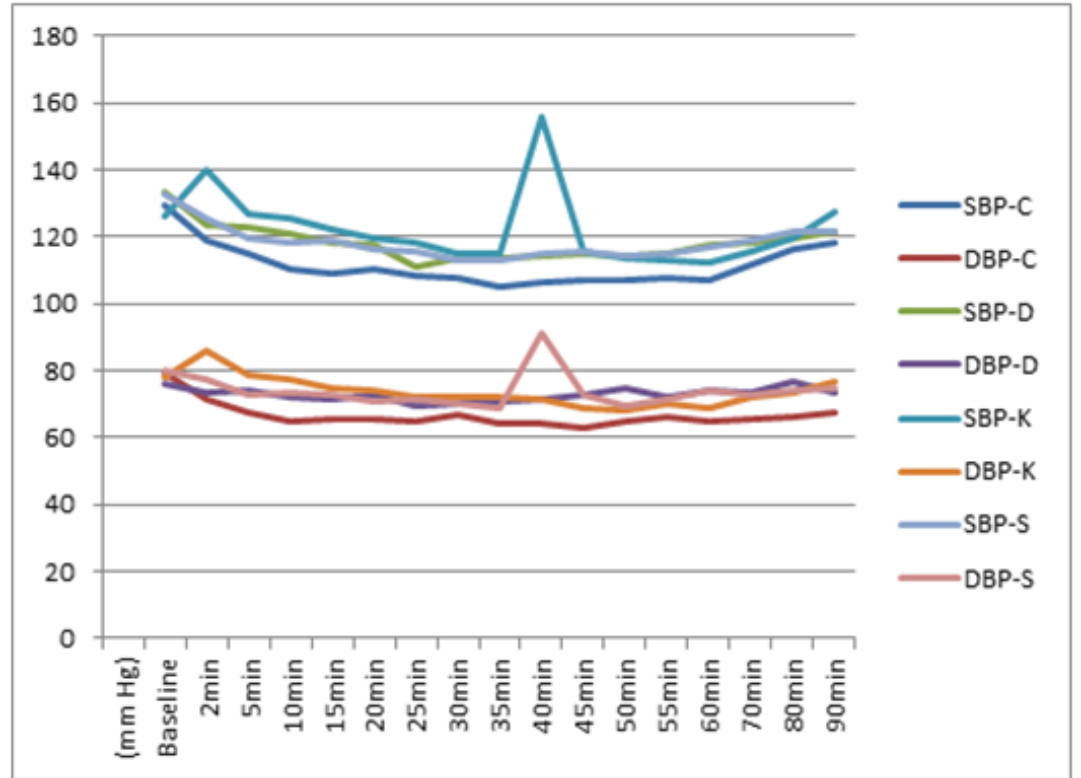

Figure 2: Trends in Systolic and Diastolic Blood Pressure

The figure 3 is showing the variation in the temperature among the four groups. There was a greater fall in core body temperatures in the placebo group as compared with the ketamine, clonidine and dexmedetomidine groups in our study.

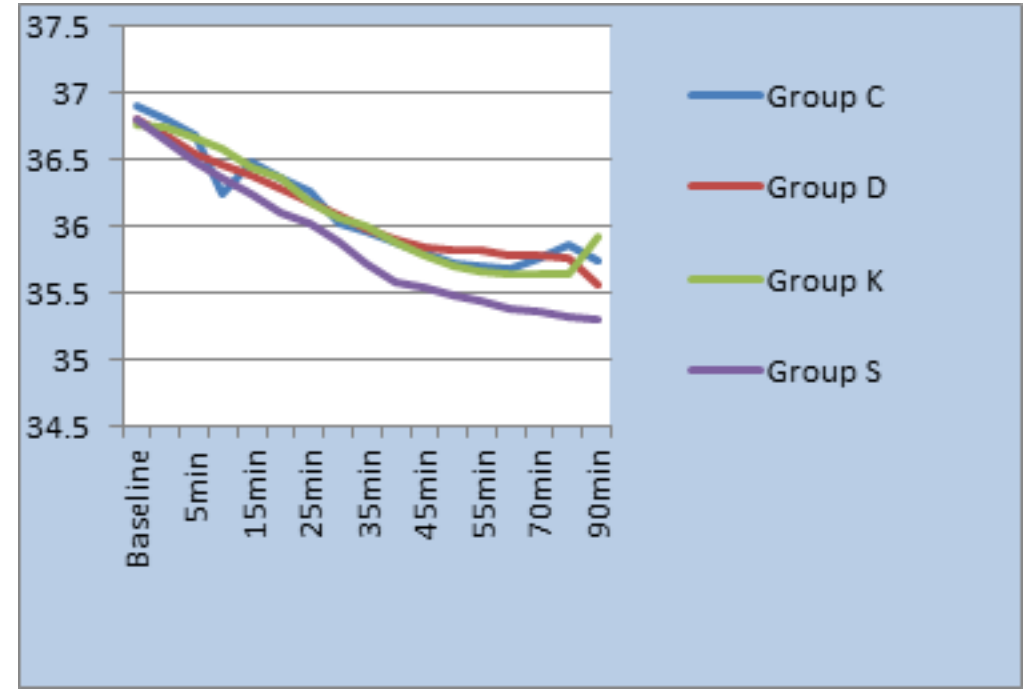

Figure 3: Trends in Core Body Temperature

Around 24 out 25 patients (96\%) in Group D didn't appear to develop shivering.

As against 21 patients and 2 patients in Group $S$ who developed grade 3 and grade 2 of shivering respectively when graded using Tsai and Chu scale. This finding was statistically significant. Comparatively in Group C the shivering was prevented in only 16 out of 25(64\%) and in Group K 5 out of $25(20 \%)$. 


\begin{tabular}{|c|c|c|c|c|c|c|c|c|c|}
\hline \multirow{2}{*}{$\begin{array}{c}\text { Shivering } \\
\text { scale }\end{array}$} & \multicolumn{2}{|c|}{$\begin{array}{c}\text { Group C } \\
(n=25)\end{array}$} & \multicolumn{2}{|c|}{$\begin{array}{c}\text { Group D } \\
(n=25)\end{array}$} & \multicolumn{2}{|c|}{$\begin{array}{c}\text { Group K } \\
(n=25)\end{array}$} & \multicolumn{2}{|c|}{$\begin{array}{c}\text { Group S } \\
(n=25)\end{array}$} & \multirow{2}{*}{$\begin{array}{c}P \\
\text { value }\end{array}$} \\
\hline & No & $\%$ & No & $\%$ & No & $\%$ & No & $\%$ & \\
\hline Grade 0 & 16 & 64.0 & 24 & 96.0 & 5 & 20.0 & 2 & 8.0 & $<0.001^{* *}$ \\
\hline Grade 1 & 1 & 4.0 & 1 & 4.0 & 0 & 0.0 & 0 & 0.0 & 1.000 \\
\hline Grade 2 & 7 & 28.0 & 0 & 0.0 & 9 & 36.0 & 2 & 8.0 & $<0.001^{* *}$ \\
\hline Grade 3 & 1 & 4.0 & 0 & 0.0 & 11 & 44.0 & 21 & 84.0 & $<0.001^{* *}$ \\
\hline Grade 4 & 0 & 0.0 & 0 & 0.0 & 0 & 0.0 & 0 & 0.0 & - \\
\hline
\end{tabular}

No significant untoward side-effects were seen in all the four groups. Hallucination was not observed in any of the groups. Dexmedetomidine causes significant grades 3 sedation as compared with placebo, clonidine and ketamine. $(<0.001)$.

DISCUSSION: Central adrenergic receptors have an important place in the modulation of shivering after anesthesia. ${ }^{10}$ The importance of clonidine, which is an adreno receptor agonist, in the treatment and prevention of shivering has been well-established in various studies. Dexmedetomidine, on the other hand, is a short acting $\alpha 2$ mimetic with less hypotensive effect and an added a sedative effect.

Dexmedetomidine is used for the sedation of mechanically ventilated patients in the intensive care unit. Thus, it has been rarely used for the prevention of vasoconstriction and shivering during spinal anesthesia. ${ }^{11}$

Dexmedetomidine is a potent $\alpha_{2}$-adrenoceptor agonist with an eight times higher affinity for the $\alpha_{2}$-adrenoceptor than clonidine. Dexmedetomidine has sedative and analgesia-sparing effects via central actions in the locus coeruleus and in the dorsal horn of the spinal cord, respectively. ${ }^{12}$

In our study we found that dexmedetomidine decreased the incidence of shivering and sedated the patient effectively. In a study conducted in 2007 by Burhanettin usta et al,13 it was found that Dexmedetomidine exerts its dual effects while avoiding vasoconstriction and increasing the level of the shivering threshold.

Redistribution of core temperature during regional anesthesia is typically restricted to the legs, and therefore core temperature decreases about half as much during regional anesthesia as during general anesthesia. ${ }^{14}$ In contrast to these changes, vasoconstriction and shivering are restricted to the upper body during spinal anesthesia.

Dexmedetomidine displays specific and selective $\alpha 2$-adrenoceptor agonism in the brain and spinal cord. The responses to activation of these receptors include decreased sympathetic tone with attenuation of the neuroendocrine and hemodynamic responses to anesthesia and surgery. Thus, dexmedetomidine can attenuate the unwanted effects of shivering provoked by hypothermia, such as increased catecholamine concentrations, oxygen consumption, blood pressure, and heart rates. ${ }^{15-16}$

Dexmedetomidine exerts its dual effects while avoiding vasoconstriction and increasing the level of the shivering threshold. Bicer and colleagues ${ }^{12}$ found the incidence of shivering as $15 \%$ with dexmedetomidine and 55\% with placebo following general anesthesia.

In Jaakola study17 in Intravenous regional anesthesia cases where iv $1 \mu \mathrm{g} / \mathrm{kg}$ dexmedetomidine was used in premedication and in another study where dexmedetomidine was used in 
order to prevent post-anesthesthetic shivering at a loading dose of $1 \mu \mathrm{g} / \mathrm{kg}$, respiratory depression was not reported.

In our study we found that Ketamine administration was associated with lesser incidence of shivering. There was no significant hypertension and tachycardia associated. Similar finding was elicited by Sagir et al. in his study. ${ }^{18} \mathrm{He}$ concluded that prophylactic ketamine $0.5 \mathrm{mg} / \mathrm{kg}$ may be administered in patients with high expectancy of shivering. But Dexmedetomidine was found to be superior to ketamine in prevention of shivering.

CONCLUSION: We conclude that giving either Dexmedetomidine $1 \mu \mathrm{g} / \mathrm{kg}$, ketamine $0.5 \mathrm{mg} / \mathrm{kg}$ or clonidine $75 \mu \mathrm{g}$ i.v. prophylactically just before neuraxial blockade, significantly decreased the incidence of shivering respectively. Dexmedetomidine has an added advantage of higher sedation score and better haemodynamic stability.

\section{REFERENCES:}

1. Sellden E, Lindahl S. Aminoacid-induced thermogenesis reduces hypothermia during anaesthesia and shortens hospital stay. Anesth analg. 1999; 89: 1551-6.

2. Berti M, Fanelli G, Casati A, et al. Hypothermia prevention and treatment. Anaesthesia. 1998; 53 (Suppl.2): 46-7.

3. Joris J, Ozaki N, Sessler D, et al. Epidural anesthesia impairs both central and peripheral thermoregulatory control during general anesthesia. Anesthesiology. 1994; 80: 268-77.

4. Frank SM, El-Rahmany HK, Cattaneo CG, Barns RA. Predictors of hypothermia during spinal anesthesia. Anesthesiology. 2000; 92: 1330-4.

5. Glosten B, Sessler DI, Faure EA, Karl L, Thisted RA. Central temperaturechanges are poorly perceived during epidural anesthesia. Anesthesiology.1992; 77: 10-6.

6. Ozaki M, Kurz A, Sessler DI, Lenhardt R, Schroeder M, Moayeri A, Noyes KM, Rotheneder E. Thermoregulatory thresholds during epiduraland spinal anesthesia. Anesthesiology. 1994; 8: 282: 8.

7. Bhattacharya PK, Bhattacharya L, Jain RK, Agrarwal RC. Post anaesthesia shivering (PAS): A review. Indian J Anaesth. 2003; 47 (2): 88-93.

8. Tsai YC, Chu KS. A comparison of tramadol, amitriptyline, andmeperidine for postepidural anesthetic shivering in parturients. Anesth Analg. 2001; 93: 1288-92.

9. Macintyre PE, Pavlin EG, Dwersteg JF. Effect of meperidine on oxygenconsumption, carbon dioxide production, and respiratory gas exchangein postanesthesia shivering. Anesth Analg. 1987; 66: 751.

10. Anataa R, Jaakola ML, Kallio A et al. Reduction of the minimum alveolar concentration of isoflurane by dexmedetomidine. Anesthesiology. 1997; 86: 1055-6.

11. Elvan EG, Oç B, Uzun S, Karabulut E, Coşkun F, Aypar U. Dexmedetomidine and postoperative shivering in patients undergoing elective abdominal hysterectomy. Eur J Anaesthesiol. 2008; 255: 357-64.

12. Bicer C, Esmaoglu A, Akin A, Boyaci A. Dexmedetomidine and meperidine prevent postanesthetic shivering. European journal of anaesthesiology 2006; 23: 149-53.

13. Burhanettin Usta, Muhammet Gozdemir, et al. Dexmedetomidine for the prevention of shivering during spinal anesthesia, clinics (Sao Paulo).2011 July: 66 (7); 1187-1191. 
14. Matsukawa T, Sessler DI, Sessler AM, Schroeder M, Ozaki M, Kurz A, Cheng C. Heat flow and distribution during induction of general anesthesia. Anesthesiology. 1995; 82: 662-73.

15. Frank SM, Higgins MS, Breslow MJ, Fleisher LA, Gorman RB, Sitzmann JV, et al. The catecholamine, cortisol, and hemodynamic responses to mild perioperative hypothermia. Anesthesiology.1995; 82:83-93.

16. Kurz A, Sessler DI, Narzt E, Bekar A, Lenhardt R, Huemer G. Postoperative hemodynamic and thermoregulatory consequences of intraoperative core hypothermia. J Clin Anesth. 1995; 7: 359-66.

17. Jaakola ML. Dexmedetomidine premedication before intravenous regional anesthesia in minor outpatient hand surgery. Journal of clinical anesthesia 1994; 6:204-11.

18. Sagir O, Gulhas N, Toprak H, Yucel A, Begec Z, Ersoy O. Control of shivering during regional anaesthesia: Prophylactic ketamine and granisetron. Acta Anaesthesiol Scand. 2007; 51: 44-9.

\section{AUTHORS:}

1. Shreyavathi R.

2. A. K. Kavitha

3. Raghavendra Rao R. S.

4. Bhaskara B.

\section{PARTICULARS OF CONTRIBUTORS:}

1. Associate Professor, Department of Anaesthesiology, Bangalore Medical College and Research Institute, Bangalore.

2. Post Graduate, Department of Anaesthesiology, Bangalore Medical College and Research Institute, Bangalore.

3. Professor and HOD, Department of Anaesthesiology, Bangalore Medical College and Research Institute, Bangalore.
4. Assistant Professor, Department of Anaesthesiology, Bangalore Medical College and Research Institute, Bangalore.

\section{NAME ADDRESS EMAIL ID OF THE} CORRESPONDING AUTHOR:

Shreyavathi R,

Associate Professor,

Department of Anesthesiology,

BMCRI, Bangalore.

Email: shreyamurthy8993@gmail.com

Date of Submission: 04/09/2014. Date of Peer Review: 05/09/2014. Date of Acceptance: 11/09/2014. Date of Publishing: 17/09/2014. 